\title{
Технико-экономический анализ
} установки по ожижению азота

\author{
() С.И. Хуциева, А.Е. Митрузаев, А.Н. Паркин, А.Е. Бром \\ МГТУ им. Н.Э. Баумана, Москва, 105005, Россия
}

Проведен технико-экономический анализ производства и использования установки по ожижению азота. Особая актуальность решения этой проблемь связана с техническо-экономическим обоснованием при выборе оптимальных теплообменных аппаратов (ТА), подтверждающим общую эффективность и иелесообразность их производства и эксплуатации. Выведена зависимость удельных затрат от стоимости электроэнергии и удельной стоимости ТА, используемых в установке указанного типа, важная для существенного повышения эффективности энергетических затрат. Приведены схема и описание установки по ожижению азота, ее технические параметры, показана возможность повышения ее экономической эффективности. Схема конструкиии витых ТА дополнена расчетами их геометрических параметров. Представлены результаты расчета коммерческих параметров эффективности: срока окупаемости установки и возможной прибыли.

Ключевые слова: технико-экономический анализ, ожижитель азота, удельные годовые затраты, технический анализ, экономические расчеты, коммерческие параметры эффективности.

Постановка проблемы. В настоящее время существует проблема выбора теплообменных аппаратов (ТА) для энергетических установок, так как ТА оказывают большое влияние на эффективность установки в целом. Эта проблема обусловлена различием в стоимости электроэнергии, а также разной стоимостью приведенной массы TA на 1 кг. Выбор ТА необходимо обосновать как с технической, так и с экономической точки зрения, т. е. провести технико-экономический анализ установки $[1,2]$.

Установка по ожижению азота (рис. 1) предназначена для сжижения и слива азота в криогенную емкость. Применительно к установке данного типа осуществлен технико-экономический анализ и определены коммерческие параметры ее эффективности.

Представленная на рисунке установка состоит из компрессорной машины КМ, теплообменника-охладителя ТА1, теплообменникаконденсатора ТА2, детандера Д, дроссельного вентиля ДР и сепаратора С. Газообразный азот при давлении 0,1 МПа поступает в компрессор К, где сжимается до давления 1,7 МПа. После охлаждения в водяных теплообменниках компрессора прямой поток разделяется на два потока: сжижаемый и детандерный (идущий на дентандер). Детандерный поток поступает в теплообменник ТА1, где охлаждается 


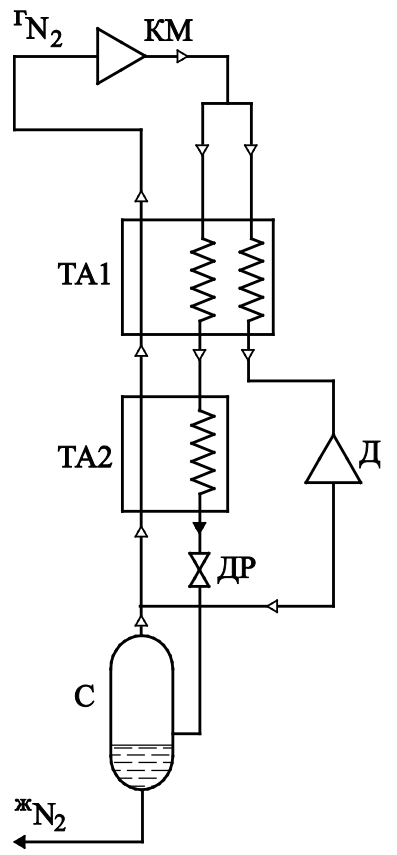

Рис. 1. Схема ожижителя азота

до температуры $154 \mathrm{~K}$, затем поступает в детандер Д, в котором расширяется до давления 0,11 МПа. Детандерный поток смешивается с обратным потоком, идущим из сепаратора C.

Сжижаемый поток поступает последовательно в теплообменники ТА1 и ТА2, где охлаждается до температуры 85 K, затем дросселируется и попадает в сепаратор $\mathrm{C}$, где происходит выделение жидкой фазы из парожидкостной смеси.

Газовый поток из сепаратора $\mathrm{C}$ смешивается с расширенным детандерным потоком, затем смешанный поток проходит последовательно теплообменники ТА2 и ТА1, нагреваясь до температуры 298 К. После смешивания с газообразным азотом он подается на всасывание в КМ.

Технический анализ. Одной из основных характеристик ТА является эффективность $\varepsilon$, определяемая NTU-методом. Для упрощения расчетов в настоящей работе эффективность ТА находят через коэффициент $k$, зависящий от минимальной разности температур двух теплоносителей в произвольном сечении ТА (рис. 2):

$$
\varepsilon=\frac{Q}{Q_{\text {идеал }}},
$$

где $\varepsilon$ - эффективность ТА; $Q$ - теплопроизводительность ТА; $Q_{\text {идеал }}$ - предельное значение теплопроизводительности ТА $(k=0)$.

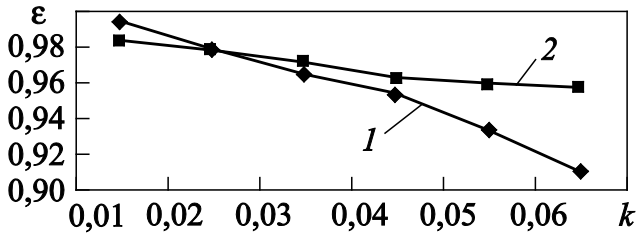

Рис. 2. Зависимость эффективности $\varepsilon$ ТА от коэффициента $k$ :

$$
1 \text { - TA } 1 ; 2-\mathrm{TA} 2
$$

В данном исследовании предлагается варьировать значение минимального сближения температур теплоносителей в ТА в зависимости от средней логарифмической температуры по обратному потоку 
[3, 4]. Эффективность такого подхода иллюстрируют следующие расчеты:

$$
\begin{gathered}
\Delta T_{\min }=\theta k ; \\
\theta=\frac{T_{2}-T_{1}}{\ln \left(T_{2} / T_{1}\right)} .
\end{gathered}
$$

Здесь $\Delta T_{\min }$ - минимальное сближение температур двух теплоносителей; $\theta$ - средняя логарифмическая температура по обратному потоку; $k$ - коэффициент пропорциональности; $T_{1}, T_{2}$ - температура обратного потока соответственно на входе и выходе ТА.

Результаты расчета схемы ожижителя для различных значений $k$ приведены в табл. 1.

Таблица 1

Зависимость основных параметров ТА от коэффициента $k$

\begin{tabular}{|c|c|c|c|c|c|c|c|c|}
\hline$k$ & $\Delta T_{\min 1}, \mathrm{~K}$ & $\Delta T_{\min 2}, \mathrm{~K}$ & $\Delta \theta_{1}, \mathrm{~K}$ & $\Delta \theta_{2}, \mathrm{~K}$ & $Q_{1}, \mathrm{KBT}$ & $Q_{2}, \mathrm{KB \textrm {T }}$ & $X$ & $D$ \\
\hline 0,01 & 1,958 & 1,007 & 10,23 & 7,099 & 596,5 & 122,9 & 12,39 & 86,59 \\
\hline 0,02 & 3,885 & 2,003 & 13,15 & 8,633 & 596,7 & 119,4 & 12,02 & 86,92 \\
\hline 0,03 & 5,780 & 2,987 & 15,54 & 9,886 & 596,9 & 115,9 & 11,64 & 87,24 \\
\hline 0,04 & 7,646 & 3,961 & 17,66 & 11,070 & 597,1 & 112,4 & 11,24 & 87,53 \\
\hline 0,05 & 9,481 & 4,924 & 19,64 & 12,170 & 597,2 & 109,0 & 10,90 & 87,82 \\
\hline 0,06 & 11,300 & 5,880 & 21,50 & 13,260 & 597,8 & 105,4 & 10,50 & 88,10 \\
\hline
\end{tabular}

Примечание: $\Delta T_{\min 1}, \Delta T_{\min 2}-$ минимальное сближение температур в теплообменниках TA1 и ТA2; $\Delta \theta_{1}, \Delta \theta_{2}$ - логарифмическая разность температур в теплообменниках ТА1 и ТА2; $Q_{1}, Q_{2}$ - тепловая нагрузка в теплообменниках ТА1 и TA2; $X$ - доля полученного жидкого азота (производительность установки); $D$ - доля потока, который идет на детандер после теплообменника TA1.

Зависимость производительности $X$ установки от значений $k$ представлена на рис. 3.

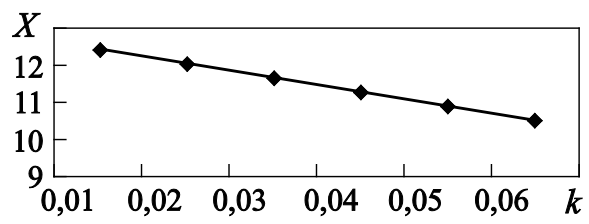

Рис. 3. Производительность $X$ установки в зависимости от коэффициента $k$

Конструкция ТА, применяемых в рассматриваемой установке, состоит из витых медных труб, оребренных медной проволокой (рис. 4). Остальные детали ТА выполнены из стали марки 12X18Н10T. 

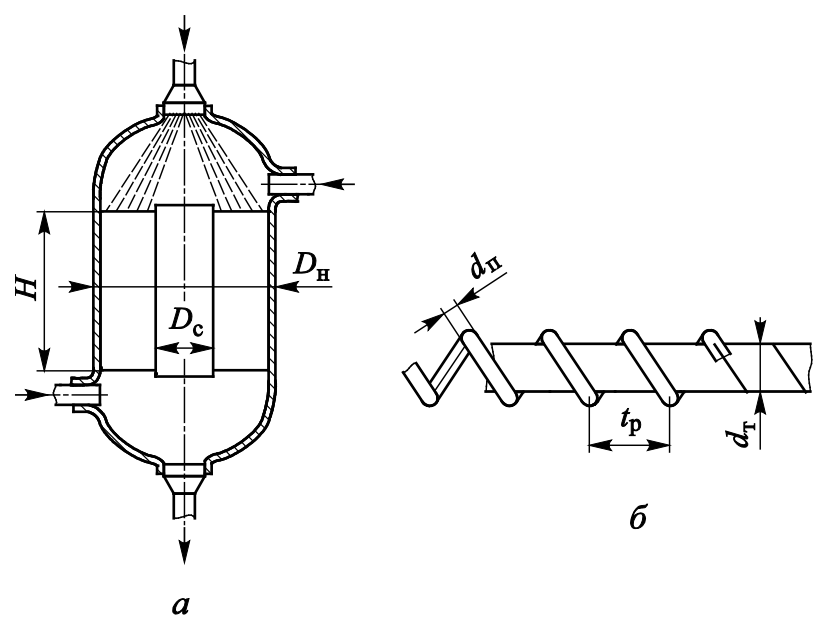

$\sigma$

Рис. 4. Конструкция витых ТА и параметры трубы:

$H$ - высота навивки; $D_{\text {с }}$ - диаметр сердечника; $D_{\text {н }}$ - наружный диаметр; $d_{\mathrm{T}}=8 \times 1-$ диаметр труб; $d_{\text {п }}=1,5$ мм - диаметр прово-

локи; $t_{\mathrm{p}}=5$ мм - шаг оребрения

Расчет ТА выполнен по методике расчета витых теплообменных аппаратов [5]. Результаты расчета представлены в табл. 2 и 3.

Таблица 2

Геометрические параметры теплообменника ТА1 в зависимости от коэффициента $k\left(D_{\mathrm{H}}=0,8 \mathrm{мм}\right.$, число труб 241)

\begin{tabular}{|c|c|c|c|c|}
\hline$k$ & $\begin{array}{c}\text { Высота навивки, } \\
\text { мм }\end{array}$ & $\begin{array}{c}\text { Площадь поверхности } \\
\text { теплопередачи, }{ }^{2}\end{array}$ & $\begin{array}{c}\text { Длина труб, } \\
\text { м }\end{array}$ & $\begin{array}{c}\text { Масса навивки, } \\
\text { кг }\end{array}$ \\
\hline 0,01 & 1800 & 524,8 & 9768 & 2,84 \\
\hline 0,02 & 1385 & 406,2 & 7563 & 2,2 \\
\hline 0,03 & 1173 & 342,5 & 6374 & 1,85 \\
\hline 0,04 & 1032 & 300,5 & 5593 & 1,6 \\
\hline 0,05 & 921 & 269 & 5008 & 1,5 \\
\hline 0,06 & 845 & 245,8 & 4576 & 1,3 \\
\hline
\end{tabular}

Таблица 3

Геометрические параметры теплообменника ТА2 в зависимости от коэффициента $k\left(D_{\mathrm{H}}=0,6 \mathrm{Mм}\right.$, число труб 169)

\begin{tabular}{|c|c|c|c|c|}
\hline$k$ & $\begin{array}{c}\text { Высота навивки, } \\
\text { мм }\end{array}$ & $\begin{array}{c}\text { Площадь поверхности } \\
\text { теплопередачи, } \mathbf{m}^{2}\end{array}$ & $\begin{array}{c}\text { Длина труб, } \\
\text { м }\end{array}$ & $\begin{array}{c}\text { Масса навивки, } \\
\text { кг }\end{array}$ \\
\hline 0,01 & 1568 & 253,5 & 4718 & 1,4 \\
\hline 0,02 & 1165 & 188,3 & 3507,6 & 1 \\
\hline 0,03 & 962 & 156,8 & 2919 & 0,85 \\
\hline 0,04 & 811 & 131 & 2440 & 0,71 \\
\hline 0,05 & 710 & 115,5 & 2149 & 0,62 \\
\hline 0,06 & 619 & 99,6 & 1853 & 0,54 \\
\hline
\end{tabular}

Из результатов расчета следует, что с увеличением значения $k$, т. е. с увеличением минимального сближения температур $\Delta T_{\min 1}$ и $\Delta T_{\min 2}$, 
уменьшается площадь поверхности теплопередачи $F$, а значит и стоимость ТА, уменьшается также производительность $X$ установки. Чтобы найти оптимальное значение коэффициента $k$, необходимо поставить и решить оптимизационную задачу. В качестве варианта решения такой задачи предлагается выполнить экономический расчет ТА, используемых в рассматриваемой установке.

Экономический анализ. Для оценки стоимости ТА рассчитаем удельную цену его производства. Суммарная начальная стоимость материалов (медь, сталь марки $12 \mathrm{X} 18 \mathrm{H} 10 \mathrm{~T}) \mathrm{C}=700$ руб/кг.

Стоимость прочего оборудования (инструмент рабочего, мелкие производственные материалы):

$$
C_{\text {пр }}=0,1 C=0,1 \cdot 700=70 \text { руб / кг. }
$$

Общая расчетная стоимость оборудования:

$$
C_{\text {pac }}=C+C_{\text {пр }}=700+70=770 \text { руб } / \text { кг. }
$$

Транспортные расходы (перевозка материалов и готовой установки):

$$
C_{\text {тр }}=0,1 C_{\text {pac }}=0,1 \cdot 770=77 \text { руб / кГ. }
$$

Поскольку основную наладку готовой установки выполняет компания-производитель, рассчитаем затраты на монтаж и упаковку:

$$
C_{\text {монтаж }}=0,25 C_{\text {рас }}=0,25 \cdot 770=192,5 \text { руб } / \text { кг. }
$$

Общая суммарная стоимость установки:

$$
C_{\text {общ }}=C_{\text {рас }}+C_{\text {тр }}+C_{\text {монтаж }}=770+77+192,5=1039,5 \text { руб } / \text { кг. }
$$

Налог на добавленную стоимость:

$$
\text { НДС }=0,18 C_{\text {общ }}=0,18 \cdot 1039,5=187,11 \text { руб } / \text { кг. }
$$

\begin{tabular}{|c|c|c|}
\hline Статьи затрат & $\begin{array}{c}\text { Процентная ставка } \\
\text { на затраты }\end{array}$ & $\begin{array}{l}\text { Всего, } \\
\text { руб/кг }\end{array}$ \\
\hline Азотная установка & Цопт & 1226,61 \\
\hline Транспортные расходы (готовое изделие) & $0,07 Ц_{\text {опт }}$ & 85,90 \\
\hline Трубопроводы и арматура & $0,05 Ц_{\text {опт }}$ & 61,30 \\
\hline Монтаж электросилового оборудования & $0,15 \bigsqcup_{\text {опт }}$ & 184,00 \\
\hline Монтажные работы по настройке & $0,15 \bigsqcup_{\text {опт }}$ & 184,00 \\
\hline Суммарные затраты & $C_{\mathrm{K}}$ & 1742,00 \\
\hline
\end{tabular}

Оптовая цена ТА для ожижителя:

$$
\bigsqcup_{\text {опт }}=C_{\text {общ }}+\text { НДС }=1039,5+187,11=1226,61 \text { руб } / \text { кг. }
$$

Результаты расчета капитальных вложений представлены в табл. 4.

\section{Капитальные вложения}


Установление тарифного разряда рабочего и отнесение работ к тому или иному разряду тарифной сетки (т. е. тарификация рабочих и работ) производится на основе единого тарифного квалификационного справочника. Фонд заработной платы с учетом тарифных ставок основных рабочих и производственных рабочих - повременщиков определяют по формуле

$$
C_{\text {з.п }}=n R \Phi_{\mathrm{p}}=6 \cdot\left(\begin{array}{c}
100 \\
300 \\
500
\end{array}\right) \cdot 1800=\left(\begin{array}{c}
1,08 \\
3,24 \\
5,40
\end{array}\right) \text { млн руб / год, }
$$

где $C_{\text {з.п }}$ - годовой фонд заработной платы (по тарифным ставкам основных рабочих); $n=6$ - число основных производственных рабочих - повременщиков; $R=\left(\begin{array}{c}100 \\ 300 \\ 500\end{array}\right)$ руб — часовая тарифная ставка среднего разряда в зависимости от завода, условий труда; $\Phi_{\mathrm{p}}=1800$ ч фонд рабочего времени одного рабочего.

Отчисление в фонды социального страхования принимаем в соответствии с законодательством РФ:

1) Пенсионный фонд РФ - $22 \%, K_{\text {п.ф }}=0,22$;

2) фонд социального страхования - 2,9 \%, $K_{\text {с.с }}=0,029$;

3) взнос на обязательное медицинское страхование (OMC) - 5,1 \%, $K_{\mathrm{OMC}}=0,051$.

Общие отчисления составляют $30 \%$ :

$$
C_{\phi}=0,3 C_{3 . \Pi}=0,3 \cdot\left(\begin{array}{c}
1,08 \\
3,24 \\
5,40
\end{array}\right)=\left(\begin{array}{l}
0,32 \\
0,97 \\
1,62
\end{array}\right) \text { млн руб / год. }
$$

Амортизацию основных средств целесообразно рассчитывать по линейному методу. При этом списание первоначальной стоимости основных средств осуществляется равными долями в течение срока полезного использования с учетом годовой нормы амортизации.

Годовые амортизационные отчисления по каждому виду основных средств рассчитаем по формуле $C_{\mathrm{a}}=C_{\mathrm{\kappa}} \mathrm{H}_{\mathrm{a}} / 100$, где $C_{\mathrm{\kappa}}$ - планируемая среднегодовая стоимость основных средств (капитальные затраты), руб; $\mathrm{H}_{\mathrm{a}}$ - годовая норма амортизации, \%.

Годовую норму амортизации определим для каждого вида основных средств по формуле $\mathrm{H}_{\mathrm{a}}=100 \%$ / СПИ, где СПИ - срок полезного использования объекта основных средств, годы. 
Годовую норму амортизации и амортизационных отчислений по каждому виду основных средств можно рассчитать следующим обра3ом:

здания

$$
\mathrm{H}_{\text {а.зд }}=\frac{100 \%}{59}=1,69 \% \text {; }
$$

машины и оборудование

$$
\mathrm{H}_{\text {а.маш }}=\frac{100 \%}{40}=2,5 \% \text {; }
$$

вычислительная техника

$$
\mathrm{H}_{\mathrm{a} . \text { вч }}=\frac{100 \%}{5}=20 \% .
$$

Результаты расчета амортизационных отчислений представлены в табл. 5.

Таблица 5

\section{Амортизационные отчисления}

\begin{tabular}{|l|c|c|}
\hline \multicolumn{1}{|c|}{$\begin{array}{c}\text { Статьи затрат (амортизационные } \\
\text { отчисления) }\end{array}$} & $\begin{array}{c}\text { Процентная ставка } \\
\text { на затраты }\end{array}$ & Итого, руб. \\
\hline Здания & $\mathrm{H}_{\text {а.зд }} C_{\mathrm{K}}$ & 29,520 \\
\hline Машины и оборудование & $\mathrm{H}_{\text {а.маш }} C_{\mathrm{K}}$ & 43,540 \\
\hline Вычислительная техника & $\mathrm{H}_{\text {а.вч }} C_{\mathrm{K}}$ & 348,364 \\
\hline Суммарные затраты & $C_{\mathrm{a}}$ & 421,424 \\
\hline
\end{tabular}

Суммарную среднюю массу $m_{\mathrm{cp}}$ теплообменников ТА1 и ТА2 примем равной 3000 кг.

Найдем общую стоимость ТА на единицу массы с учетом процесса производства:

$$
Ц=C_{\mathrm{\kappa}}+C_{\mathrm{a}}+\frac{C_{3 . \Pi}+C_{\phi}}{m_{\mathrm{cp}}}=\left(\begin{array}{c}
2631 \\
3567 \\
4503
\end{array}\right) \text { руб/кг, }
$$

при этом общая стоимость затрат на производство ТА

$$
\text { OC_ } \Pi \approx Ц m .
$$

Здесь Ц - удельная стоимость ТА; $m$ - масса ТА.

Важным элементом ожижителей является компрессор - одна из наиболее энергозатратных частей установки. Будем считать, что годовые затраты на эксплуатацию формируются из затрат на электроэнергию. Тогда общая стоимость затрат на эксплуатацию ТА

$$
\mathrm{OC} \_\ni=\tau C_{\ni} N_{e} \text {, }
$$


где $\tau=5000$ ч — продолжительность работы; $C_{э}=\left(\begin{array}{c}1,00 \\ 3,00 \\ 5,03\end{array}\right)$ руб / (кВт·ч) стоимость электроэнергии; $N_{e}$ - мощность, затрачиваемая на привод компресcopa,

$$
N_{e}=\frac{T_{\text {o.c }}\left(s_{1}-s_{2}\right)-\left(h_{1}-h_{2}\right)}{\eta_{t}}=707,7 \text { кВт, }
$$

где $T_{\text {о.с }}=293 \mathrm{~K}$ - температура окружающей среды; $s_{1}, s_{2}$ - энтропия азота до и после компрессора; $h_{1}, h_{2}$ — энтальпия азота до и после компрессора; $\eta_{t}=0,63$ - изотермический КПД компрессора [6].

Определим удельные приведенные годовые затраты [7]:

$$
\Pi_{\text {уд }}=\frac{\text { OC_ } \Pi\left(E_{\text {н }}+C_{\text {авт }}+C_{\mathrm{p}}\right)+\mathrm{OC}_{-} \ni}{G_{\mathrm{N}_{2}} X \tau},
$$

где $E_{\mathrm{H}}=0,15$ - нормативный коэффициент эффективности капитальных затрат; $C_{\text {авт }}=0,128$ - доля общей стоимости, отчисляемая на автоматизацию ТА; $C_{\mathrm{p}}=0,055$ - доля общей стоимости, отчисляемая на ремонт ТА; $G_{\mathrm{N}_{2}}=13394$ кг/ч — расход азота, поступающего в компрессор.

Результаты расчета общей стоимости затрат на производство для трех вариантов удельной стоимости ТА приведены ниже (затраты на эксплуатацию в зависимости от стоимости электроэнергии OC_Э составили соответственно 3,54/10,62/17,8 млн руб / год):

$\begin{array}{cc}k & \text { ОС_П, млн руб } \\ 0,01 & 14,41 / 19,53 / 24,65 \\ 0,02 & 11,01 / 14,92 / 18,84 \\ 0,03 & 9,24 / 12,53 / 15,82 \\ 0,04 & 7,98 / 10,83 / 13,67 \\ 0,05 & 7,12 / 9,65 / 12,18 \\ 0,06 & 6,39 / 8,67 / 10,94\end{array}$

Целью расчетов общей стоимости затрат на производство и эксплуатацию является нахождение оптимального значения $k$, при котором удельные приведенные годовые затраты будут минимальными. Зависимость этих затрат от значения $k$ для $C_{\ni}=3$ руб/(кВт·ч) и различной удельной стоимости ТА Ц представлена на рис. 5. 


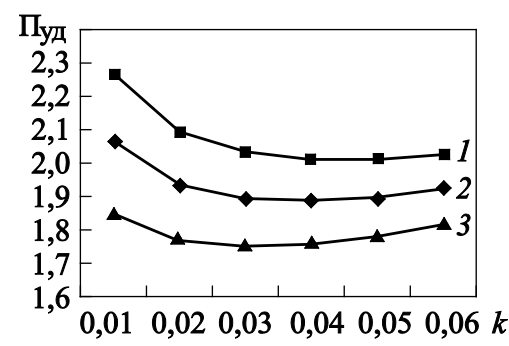

Рис. 5. Зависимость удельных приведенных годовых затрат $\Pi_{\text {уд }}$ от коэффициента $k$ : $1-Ц=4503$ руб/кг; $2-3567$ руб/кг; $3-2631$ руб/кг

Из графиков ясно, что с увеличением удельной стоимости ТА оптимальное значение $k$ будет увеличиваться и экономически целесообразнее использовать менее эффективные ТА. Например, при $C_{\ni}=3$ руб/(кВт·ч) и $Ц=3567$ руб/кг оптимальное значение $k=0,04$, при этом $\Pi_{\text {уд }}=1,889$ руб/(1 кг жидкого $\mathrm{N}_{2} \cdot$ год), а при Ц $=4503$ руб/кг оптимальное значение $k=0,05$, при этом $\Pi_{\text {уд }}=2,01$ руб/(1 кг жидкого $\mathrm{N}_{2} \cdot$ год).

В зависимости от стоимости электроэнергии и стоимости 1 кг ТА оптимальные значения $k$ будут изменяться (табл. 6).

Таблица 6

Оптимальные значения коэффициента $\boldsymbol{k}$ при различной удельной стоимости ТА Ц и стоимости электроэнергии $C_{3}$

\begin{tabular}{|c|c|c|c|}
\hline \multirow{2}{*}{$C_{э}$, руб/(кВт·ч) } & \multicolumn{3}{|c|}{ Ц, руб/кг } \\
\cline { 2 - 4 } & 2631 & 3567 & 4503 \\
\hline 1,00 & 0,06 & $>0,06$ & $>0,06$ \\
\hline 3,00 & 0,03 & 0,04 & 0,05 \\
\hline 5,03 & 0,02 & 0,03 & 0,03 \\
\hline
\end{tabular}

Полученные расчетом оптимальные значения Пуд и $k$ для различных значений удельной стоимости ТА и стоимости электроэнергии приведены на рис. 6.

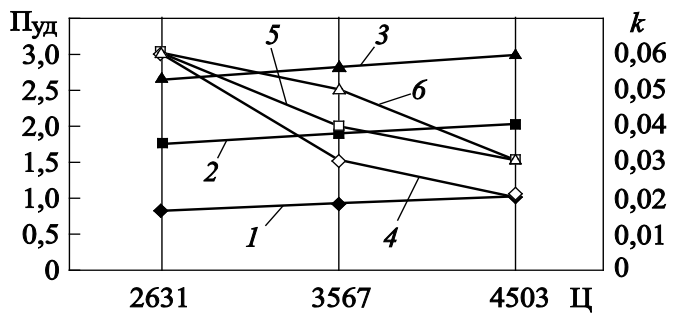

Рис. 6. Зависимость оптимальных значений $\Pi_{\text {уд }}$ (кривые 1-3) и $k$ (кривые 4-6) от удельной стоимости ТА Ц при различной стоимости электроэнергии:

$1,4-\mathrm{C}_{э}=1$ руб/(кВт·ч); 2, $5-3$ руб/(кВт·ч); $3,6-5,03$ руб/(кВт・ч) 
Данные, обобщенные в табл. 6 и представленные на рис. 6, подтверждают, что с увеличением стоимости электроэнергии оптимальное значение $k$ уменьшается, следовательно, экономически целесообразнее использовать более эффективные ТА.

Важным экономическим параметром является срок окупаемости установки $t$, годы [8]:

$$
t=\frac{\mathrm{OC}_{-} \Pi}{\Pi-\mathrm{OC}_{-} \ni}
$$

где $\Pi=C_{\mathrm{N}_{2}} G_{\mathrm{N}_{2}} X \tau$ - прибыль, полученная от продажи жидкого азота $\left(C_{\mathrm{N}_{2}}=40\right.$ руб/кг - стоимость 1 кг жидкого азота; $G_{\mathrm{N}_{2}} X-$ расход жидкого азота, кг/ч).

Результаты расчета прибыли, полученной от продажи жидкого азота, приведены ниже:

\begin{tabular}{cccccc}
$k$ & \multicolumn{2}{c}{ П, млн руб. } & $k$ & \multicolumn{2}{c}{ П, млн руб. } \\
0,01 & $\ldots \ldots \ldots \ldots$. & 331,9 & 0,04 & $\ldots \ldots \ldots \ldots$ & 301,1 \\
0,02 & $\ldots \ldots \ldots \ldots \ldots$ & 322,0 & 0,05 & $\ldots \ldots \ldots \ldots$. & 292,0 \\
0,03 & $\ldots \ldots \ldots \ldots$. & 311,8 & 0,06 & $\ldots \ldots \ldots \ldots$ & 280,7
\end{tabular}

Зависимость срока окупаемости $t$ от коэффициента $k$ при различной стоимости ТА на единицу массы представлена на рис. 7. Стоимость электроэнергии не существенно влияет на срок окупаемости, поэтому расчет выполнен при средней стоимости электроэнергии $C_{\ni}=3$ руб/(кВт·ч).

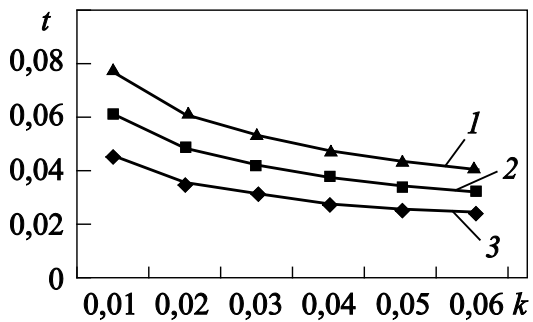

Рис. 7. Зависимость срока окупаемости $t$ от коэффициента $k$ :

$1-Ц=4503$ руб/кг; $2-3567$ руб/кг; $3-2631$ руб/кг

Выводы. Проведенное исследование с использованием предложенных для анализа методик позволяет оценить эффективность выбора ТА для установки по ожижению азота. Результаты расчетов показали, что с увеличением стоимости электроэнергии целесообразнее использовать более эффективные ТА, а с увеличением удельной стоимости ТА - менее эффективные ТА.

При выборе вариантов совершенствования конструкции витых ТА требуются дополнительные расчеты их геометрических парамет- 
ров, а также показателей удельной цены их производства и эксплуатации, что подтверждает их оптимальные характеристики техникоэкономической эффективности. Проведенный экономический анализ показывает, что стоимость ТА целесообразно оценивать с учетом суммарной начальной стоимости материалов, оплаты труда работников по основной и повременной занятости, капитальных и других расходов, в том числе расходов на транспорт, монтаж и упаковку готовой установки, ее наладку, осуществляемую компанией-производителем.

Общая суммарная стоимость установки должна быть рассчитана с учетом налога на добавленную стоимость, включаемого в оптовую цену ТА для ожижителя. В расчетах учитываются также предусмотренные законодательством отчисления в фонд социального страхования, Пенсионный фонд РФ и взносы на обязательное медицинское страхование.

В статье показано, что обоснование коммерческих параметров эффективности установки и ТА для нее целесообразно осуществлять на основе расчетов срока окупаемости, производительности, энергетической эффективности. Эти показатели влияют на потенциал получения прибыли от продажи жидкого азота с учетом его стоимости в текущих ценах, а также его расхода.

\section{ЛИТЕРАТУРА}

[1] Скворцов Ю.В. Организационно-экономические вопросы в дипломном проектировании. Москва, Высшая школа, 2006, 399 с.

[2] Ипатов М.И., Постников В.И. Технико-экономический анализ машин и приборов. Москва, Машиностроение, 1985, 248 с.

[3] Архаров А.М., Архаров И.А., Шевич Ю.А. Теплотехника. Москва, Изд-во МГТУ им. Н.Э. Баумана, 2004, 711 с.

[4] Архаров А.М. Основы криологии. Москва, Изд-во МГТУ им. Н.Э. Баумана, 2014, $507 \mathrm{c}$.

[5] Красникова О.К. Витые теплообменные аппараты криогенных и теплоэнергетических установок. Москва, КолосС, 2008, 176 с.

[6] Архаров А.М., Марфенина И.В. Криогенные системыл. Москва, Машиностроение, 1996, 576 с.

[7] Сакун И.А., Бамбушек Е.М., Бухарин Н.Н., Герасимов Е.Д. Тепловые $u$ конструктивные расчеты холодильных машин. Ленинаград, Машиностроение, 1987, 423 с.

[8] Денисов В.И. Технико-экономические расчеты в энергетике: методы экономического сравнения вариантов. Москва, Энергоатомиздат, 1985, 216 с.

Статья поступила в редакцию 27.01.2016

Ссылку на эту статью просим оформлять следующим образом:

Хуциева С.И., Митрузаев А.Е., Паркин А.Н., Бром А.Е. Инженерный журнал: наука и инновации, 2016, вып. 3. URL: http://engjournal.ru/catalog/pmce/mdpr/1478.html

DOI 10.18698/2308-6033-2016-03-1478 
Статья подготовлена по материалам доклада, представленного на XL Академических чтениях по космонавтике, посвященных памяти академика С.П. Королёва и других выдающихся отечественных ученых - пионеров освоения космического пространства, Москва, МГТУ им. Н.Э. Баумана, 26-29 января 2016 г.

Хуциева София Иосифовна - студентка кафедры «Холодильная, криогенная техника. Системы кондиционирования и жизнеобеспечения» МГТУ им. Н.Э. Баумана; инженер Научно-учебного комплекса «Энергомашиностроение» МГТУ им. Н.Э. Баумана. e-mail: khutsieva.sofia2012@yandex.ru

Митрузаев Александр Евгеньевич - студент кафедры «Промышленная логистика» МГТУ им. Н.Э. Баумана. e-mail: mitalex94@mail.ru

Паркин Алексей Николаевич - ассистент кафедры «Холодильная, криогенная техника. Системы кондиционирования и жизнеобеспечения» МГТУ им. Н.Э. Баумана. e-mail: parkin.aleksey@gmail.com

Бром Алла Ефимовна - д-р техн. наук, профессор кафедры «Промышленная логистика» МГТУ им. Н.Э. Баумана. e-mail: ibm3@ibm.bmstu.ru 


\title{
Feasibility analysis of the installation for the nitrogen liquefaction
}

\author{
(C) S.I. Khutsieva, A.E. Mitruzaev, A.N. Parkin, A.E. Brom
}

Bauman Moscow State Technical University, Moscow, 105005, Russia

The article presents the results of feasibility analysis and calculation of the production cost and cost of using the installation for the nitrogen liquefaction. The particular urgency of solving this problem is associated with both the technical and economic rationale for the optimum heat exchangers (HE) choice to support the overall effectiveness and expediency of their production and operation. For performing the analytical substantiation the dependence of the cost per unit on the electricity cost and the HE cost per unit used in the installation of this type is determined in the article to significantly improve the energy efficiency. For clarity, the article provides the diagram and description of the installation for nitrogen liquefaction, its technical parameters and the potential to increase economic efficiency. Structural diagram of the coil HE shown in the article is supplemented by calculations of the geometric parameters, presented in the tables. In support of commercial efficacy parameters estimated payback period of the installation and profit opportunities are presented. The technique for calculating the commercial factors as payback period, profit etc. is given in the respective tables.

Keywords: feasibility analysis, nitrogen liquefier, annual cost per unit, technical analysis, economic design, commercial efficacy parameters.

\section{REFERENCES}

[1] Skvortsov Y.V. Organizatsionno-ekonomicheskie voprosy $v$ diplomnom proektirovanii [Organizational and Economic Issues in the Graduation Design]. Moscow, Vysshaya shkola Publ., 2006, 399 p.

[2] Ipatov, M.I., Postnikov V.I. Techniko-ekonomicheskiy analiz mashin i priborov [Feasibility Analysis of Machines and Devices]. Moscow, Mashinostroenie Publ., 1985, 248 p.

[3] Arkharov A.M., Arkharov I.A., Shevich Yu. A. Teplotekhnika [Heat Engineering]. Moscow, BMSTU Publ., 2004, 711 p.

[4] Arkharov A.M. Osnovy kriologii [Fundamentals of Cryology]. Moscow, BMSTU Publ., 2014, 507 p.

[5] Krasnikova O.K. Vitye teploobmennye apparaty kriogennykh i teploenergrticheskikh ustanovok [Coil Heat Exchangers in Cryogenic and Thermal Power Plants]. Moscow, KolosS Publ, 2008, 176 p.

[6] Arkharov A.M., Marfenina I. V. Kriogennye sistemy [Cryogenic Systems]. Moscow, Mashinostroenie Publ., 1996, 576 p.

[7] Sakun I.A., Bambushek E.M., Bukharin N.N., Gerasimov E.D. Teplovye $i$ konstruktivnye raschety kholodilnykh mashin [Thermal and Structural Analysis of Refrigerating Machines]. Leningrad, Mashinostroenie Publ, 1987, 423 p.

[8] Denisov V.I. Techniko-ekonomicheskie raschety $v$ energetike: metody ekonomicheskogo sravneniya variantov [Feasibility Analysis in Power Engineering: Methods of Economic Comparison of Options]. Moscow, Energoatomizdat Publ., 1985, 216 p. 
Khutsieva S.I., student, Department of Refrigerating and Cryogenic Technology, Air Conditioning and Life Support Systems, engineer, the Center of Research and Education Power Engineering, Bauman Moscow State Technical University.

e-mail: khutsieva.sofia2012@yandex.ru

Mitruzaev A.E., student, Department of Industrial Logistics, Bauman Moscow State Technical University. e-mail: mitalex94@mail.ru

Parkin A.N., Assistant Lecture, Department of Refrigerating and Cryogenic Technology, Air Conditioning and Life Support Systems, Bauman Moscow State Technical University. e-mail: parkin.aleksey@gmail.com

Brom A.E., Dr. Sci. (Eng.), Professor Department of Industrial Logistics, Bauman Moscow State Technical University. e-mail: ibm3@ibm.bmstu.ru 